\title{
Environmental Approach for Energy Audits on Government Buildings: A Mexican Case for the Air Conditioning System
}

\author{
Luis E. Velazquez¹, Rafael Perez-Rios', Nora E. Munguia1, David S. Zepeda1', Carla Neudert², \\ Javier Esquer $^{1^{*}}$
}

\author{
${ }^{1}$ Sustainability Graduate Program, Industrial Engineering Department, University of Sonora, Hermosillo, Mexico \\ ${ }^{2}$ Freelance Sustainability Consultant, Hermosillo, Mexico \\ Email: *jesquer@industrial.uson.mx
}

How to cite this paper: Velazquez, L.E., Perez-Rios, R., Munguia, N.E., Zepeda, D.S., Neudert, C. and Esquer, J. (2018) Environmental Approach for Energy Audits on Government Buildings: A Mexican Case for the Air Conditioning System. Journal of Environmental Protection, 9, 278-293.

https://doi.org/10.4236/jep.2018.93019

Received: February 1, 2018

Accepted: March 25, 2018

Published: March 28, 2018

Copyright $\odot 2018$ by authors and Scientific Research Publishing Inc. This work is licensed under the Creative Commons Attribution International License (CC BY 4.0).

http://creativecommons.org/licenses/by/4.0/

\section{(c) (i) Open Access}

\begin{abstract}
In the face of the climate change, energy consumption is one of the main issues to be solved. Energy audits are useful tools that may contribute to develop energy efficiency initiatives. The purpose of this paper is to provide insights into how energy audits, with a scope on air conditioning (AC) systems, contribute to develop energy efficiency options for a government building in the city of Hermosillo, Mexico. The methodology is based in the energy audit framework proposed by the American Society of Heating, Refrigerating and Air-Conditioning Engineers (ASHRAE). Results show that, in a typical day of maximum consumption, AC represents $64 \%$ of the total electrical consumption, while office equipment accounted for $22 \%$, and lighting $14 \%$. Additionally, AC system has a yearly consumption of $54,419.40 \mathrm{kWh}$ with an emission estimate of 24.92 tons of $\mathrm{CO}_{2}$-eq/year. Three approaches for energy efficiency proposals were addressed through AC systems: Improvement of the operation and consumption habits, maintenance and reconditioning of facilities, and replacement of AC units. While Mexico has international commitments through environmental treaties related to contribute to climate change mitigation, this study shows that, at least one government building still produces potential impacts that can be deterred by addressing structural and behavioral changes related to AC operation. Finally, this study may be used as reference for energy efficiency practitioners or decision-making authorities in the public administration field for developing better energy policies for government buildings.
\end{abstract}




\section{Keywords}

Electricity Consumption, Energy Audits, Energy Efficiency, Environmental Impact

\section{Introduction}

\subsection{Climate Change, a General View}

Climate change is defined by the United Nations Framework Convention on Climate Change as "a change of climate which is attributed directly or indirectly to human activity that alters the composition of the global atmosphere and which is in addition to natural climate variability observed over comparable time periods" [1]. This concept includes climate attributes like precipitation patterns, winds, and ocean currents, and is usually related to a more specific phenomenon called global warming, which is referred to the "increasing average surface temperatures of the Earth over the past one to two centuries" [2].

The concentration of atmospheric carbon dioxide has been an indicator linked to climate change which has been used as evidence of the effects generated by human activities on the chemical composition of the atmosphere, including greenhouse gas (GHG) emissions, such as those created during the burning of fossil fuels [1] [3] [4]. Thus, there is currently a consensus among roughly $90 \%$ of the scientists in this field that humans are contributing to the current global warming trend [5].

To reduce and/or eliminate the adverse effects of climate change, it is necessary to implement adaptation and mitigation measures. Adaptation is the adjustment process to the current or expected climate change and its effects, and mitigation refers to a human intervention aimed to reduce GHG sources or to improve the storage of those emissions [6]. Because adaptation and mitigation both seek to address the impacts of climate change, these should not be considered divergent approaches [7]. On the contrary, the effective combination of these two concepts must be identified to obtain more sustainable results [8].

In terms of adaptation measures, in developed countries, short-term interventions have been the primary approach because that represents less risk as compared to long-term strategic planning, which has an increased vulnerability and difficulty in regards to the implementation of actions in the future [9]. For example, an irrigation system for crop deficits might be implemented where water use is limited [10]. On the other hand, with respect to mitigation measures, initiatives such as the Kyoto Protocol have been adopted at the international level since 1997 [11]. More recently, during the Conference of the Parties 21 held in Paris in 2015, the first globally binding agreement on climate change was signed [12], which requires participants to share technology, to offer financial aid, and to cooperate to reduce GHG emissions, specifically those that result from the energy, transport, and industry sectors [13]. 
In Mexico, carbon dioxide equivalent $\left(\mathrm{CO}_{2}\right.$-eq) emissions reached 748 million tons in 2010, representing a growth of $33.4 \%$ as compared to the emissions in 1990 [14]. This increase was caused by the generation and consumption of energy, which included $67.3 \%$ of the total, and agriculture which accounted for $12.3 \%$ [15]. With respect to the GHG inventory in the State of Sonora specifically, 19.8 million metric tons of $\mathrm{CO}_{2}$-eq emissions were generated by various sources, including energy at $67 \%$, agriculture at $18 \%$, industrial processes at $8 \%$, and waste at $7 \%[16]$.

\subsection{Energy Audits and Energy Efficiency}

In order to avoid a temperature increase of 5 to 6 degrees Celsius by the end of this century, energy efficiency programs must be established in all sectors across all of the countries globally [17]. Energy efficiency includes actions that reduce the amount of energy needed to satisfy the goods and services demanded by society by maintaining or increasing its quality as well as by decreasing the environmental impacts caused by the generation, transport, and consumption processes [18]. By reducing energy demand, two important objectives of sustainable development are achieved; the economy of primary resources is addressed, and the volume of emissions released into the environment is reduced [19].

Regarding the economic benefits of energy efficiency, these are almost always viable in the long term because they help to reduce emissions and strengthen energy security; however, economic incentives are necessary to develop the potential of energy efficiency and increase private financing for these initiatives in the short term [20]. Also, there are barriers to its implementation, such as the high costs of project development in relation to the value of energy savings, a lack of information required for rational decision-making, and a lack of affordable technologies that are effective given the local conditions [21].

Some countries have adopted policies and measures to increase energy efficiency levels in buildings in order to reduce their total electricity consumption [22]. In general, energy efficiency projects in public buildings must have broad objectives aimed at community development and more specific objectives regarding the realization of the project given current limitations, such as the duration, available resources, estimated costs, and the quality of the proposed energy efficiency measures [23].

One tool aimed at energy efficiency is conducting an audit that detects operational problems, improves the comfort of the occupants, and optimizes energy use in existing buildings [24] [25]. The International Organization for Standardization states that an energy audit includes a detailed review of the energy performance of an organization, a process, or both and is based on an appropriate measurement and observation of real energy performance [26].

An energy audit provides key information that can be utilized to carry out interventions to reduce what is known as the "energy efficiency gap", which con- 
sists of insufficient investment by both the public and private sectors in energy saving technologies in buildings, from which one of the primary causes for this is the lack of timely information [27]. The American Society of Heating, Refrigeration and Air Conditioning Engineers (ASHRAE) has developed an energy audit methodology that consists of three levels, which are a walk-through survey, an energy survey and analysis, and a detailed analysis of capital-intensive modifications [28].

The purpose of this paper is to provide insights into how energy audits contribute to develop energy efficiency options that can reduce the potential environmental impacts related to electricity consumption of a government building in the city of Hermosillo, Mexico.

\section{Methods}

\subsection{Energy Audit Procedure}

An Energy Audit (EA) for a government agency building located in the city of Hermosillo, Sonora in the northwestern area of Mexico. The purpose of the audit was to identify opportunities for improvement through the identification of better energy options and to promote a culture of energy efficiency among the government personnel with the ultimate goal of contributing to the reduction of greenhouse gases (GHG) emissions. The scope of the audit was the air conditioning (AC) system, which provides the indoor comfort conditions for an optimal performance of the activities carried out by the personnel in the administrative areas.

The study was carried out from September 2016 to July 2017 and covered all of the facilities. The methodology used for the EA was based on a program originally proposed by the American Society of Heating, Refrigerating and Air-Conditioning Engineers [29] under the concept Energy Audit Level II-Energy Survey and Analysis. A procedure was followed to identify opportunities for low-cost energy savings as well as energy efficiency recommendations based on the current consumption characteristics of the audited building.

The main steps involved in conducting the EA are as follows. A pre-evaluation is done to gather basic geographic data and general information of the building. An in-situ evaluation is performed to collect further data, to identify energy efficiency opportunities, and to hold preliminary meetings to explain the process to the various stakeholders. Next, an analysis is done to review all the data obtained, to prioritize the opportunity areas from lowest to highest economic cost, as well as to establish potential savings' estimates. Finally, a report is delivered at a final meeting with the stakeholders to provide explanations, recommendations, and an action plan.

\subsection{Data Collection}

To obtain and process data for the study, several instruments were utilized.

- Measuring tape: The measurement of each office, as well as the total area of 
the building, is important to determine accurately some energy indicators. In the absence of architectural blueprints of the structures, it was decided to take measurements manually of each audited area.

- Thermographic camera, Model E5 Flir: This instrument takes thermal photographs, which show the full range of temperatures present in the location through an image containing different shades of colors. The lighter and brighter colors indicate higher temperatures, and the darker colors indicate lower temperatures. Thermal images were taken with the purpose of creating a thermal map of the typical conditions in the work environment.

- Digital Camera: With this device, images of the physical conditions of the building were taken.

- Excel: Once the on-site evaluation and the collection of all data were complete, databases were generated using $\mathrm{Microsoft}^{\oplus} \mathrm{Excel}^{\otimes}$ software in order to analyze the energy results, to obtain indicators, and to study potential scenarios for the proposed recommendations.

\section{Results}

\subsection{Pre-Evaluation}

Hermosillo, Sonora, where the building is located, has a climate that ranges from dry to very dry with warmer temperatures most of the year reaching high values close to $50^{\circ} \mathrm{C}\left(122^{\circ} \mathrm{F}\right)$; consequently, the use of $\mathrm{AC}$ is necessary. The official working hours for the employees are from 8:00 a.m. to 3:00 p.m. on Monday through Friday; however, there are employees who continue to work longer into the afternoon occasionally.

The building, inaugurated in 1954, first hosted a primary school and later was adapted to serve as government offices. The total area of the building, including the exterior offices, is $790.91 \mathrm{~m}^{2}$. The original structure has been maintained; also, offices were built in several of the corridors on the ground floor and upstairs.

According to the electricity bills issued by the Federal Electricity Commission (CFE), the government building had a consumption of $96,320 \mathrm{kWh}$ over the period of November 15, 2015 to October 16, 2016. According to the Emissions Calculator for the National Emissions Registry of the Secretariat of Environment and Natural Resources and the Inter-American Development Bank [30], this consumption generated an estimated emissions volume of 44.11 tons of $\mathrm{CO}_{2}$-eq/year.

\subsection{In-Situ Evaluation}

One of the first necessary tasks was to create a blueprint of the building. Thirty-eight sections were identified within the sixteen administrative areas. For instance, the three largest administrative areas were Administration and Finance, with $110.72 \mathrm{~m}^{2}$, Environmental Management, with $108.36 \mathrm{~m}^{2}$, and Executive Commission, with $94.69 \mathrm{~m}^{2}$.

For each section of the whole administrative areas, a detailed inventory of air 
conditioning, lighting, as well as electronic and electrical office equipment was created, including information about the types of equipment, the models, the levels of power, the timeframes for typical daily use, and an estimated daily energy consumption for each. Table 1 contains an example of the information gathered during the audits for the AC inventory and Table 2 includes a summary of the inventory that was taken. A database was created with the information gathered from the AC, lighting, and office equipment, which allowed for an estimation to be calculated.

For example, in a typical day of maximum consumption, with all the devices turned on, the AC system represented $64 \%$ of the total electrical consumption, while office equipment accounted for $22 \%$, and lighting was only responsible for 14\%, as seen in Figure 1.

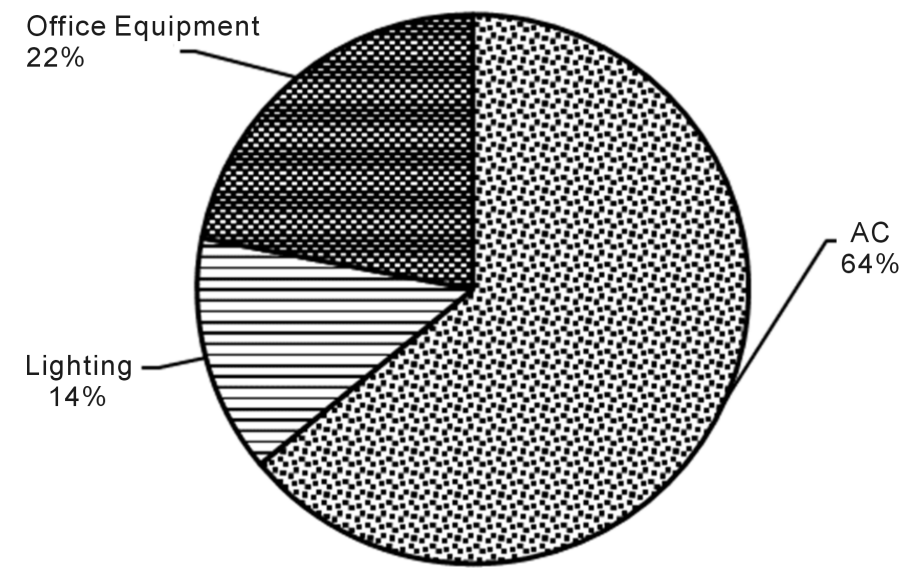

Figure 1. Electric power consumption by category. Source: Own elaboration.

Table 1. Inventory example for AC units in the Administration and Finance area.

\begin{tabular}{ccccccccc}
\hline $\begin{array}{c}\text { Administrative } \\
\text { area }\end{array}$ & Quantity & Type & Brand & $\begin{array}{c}\text { Refrigerant } \\
\text { type }\end{array}$ & $\begin{array}{c}\text { Electric } \\
\text { power W }\end{array}$ & $\begin{array}{c}\text { Time of } \\
\text { use h }\end{array}$ & $\begin{array}{c}\text { Consumption Cooling capacity } \\
\text { kWh }\end{array}$ & $\begin{array}{c}\text { BTU/h } \\
\text { B }\end{array}$ \\
\hline & 1 & Fan-coil & Lennox & R410A & 3916.0 & 7 & 36 & 36,000 \\
$\begin{array}{c}\text { Administration and } \\
\text { Finance }\end{array}$ & 1 & Mini-split & Rheem & - & 2200.0 & 7 & 178 & 24,000 \\
& 1 & Window & York & R22 & 1789.0 & 7 & 318 & 17,843 \\
\hline
\end{tabular}

Source: Own elaboration.

Table 2. Inventory summary.

\begin{tabular}{ccc}
\hline Item & Quantity & Estimated Daily Energy Consumption kWh \\
\hline Air Conditioning (AC) units & 36 & 431.91 \\
Equipment (electronic and electric) & 178 & 148.78 \\
Lighting (lamps and bulbs) & 318 & 90.30 \\
Total & & 670.99 \\
\hline
\end{tabular}

Source: Own elaboration. 
Additionally, the condition of the thermal insulation in the building was reviewed, and the various types of materials used, including their different coefficients of thermal conductivity, were identified. For instance, the external brick, the external panels $\left(\right.$ Durock $^{\circledR}$ ), internal panels (Drywall ${ }^{\circledR}$ ), glass, polycarbonate, glass windows, cast concrete used on the ceilings, and the expanded polystyrene panel used on the ceiling lamps were all noticed within the building. The characteristics of these various materials, as well as their geographical orientation, were necessary to identify so that the areas where there is greater heat transfer that is occurring between the exterior and interior of the offices could be determined.

Furthermore, the state of the windows was also recorded, including the condition of the polarizer film that some of the windows had, as shown in Figure 2. For example, the highest temperature measured on a surface of the windows was $47^{\circ} \mathrm{C}$. This window had a blacksmith structure, which faced south, and was located in the office of the Director of Climate Change and Environmental Promotion on the second floor.

A sampling of thermographic photographs, as shown in Figure 3, was conducted on the internal faces of all central points of the building surfaces of the walls, the windows, and the roof, from a distance of approximately $2 \mathrm{~m}$ depending on their orientation. The maximum temperature of $44.2^{\circ} \mathrm{C}$ was measured on the outer walls, which faced west in the Meeting Room of the Executive Committee.

Additionally, the roof conditions were also analyzed. On the top floor of the main building, a lack of maintenance was identified since the waterproofing was in poor condition and included unprotected areas, as illustrated in Figure 4.

\subsection{Analysis}

The consumption pattern identified a monthly average of $8026.66 \mathrm{kWh}$, with an average cost of $\$ 2.00$ Mexican pesos, the equivalent of $\$ 0.1081$ US dollars [31],

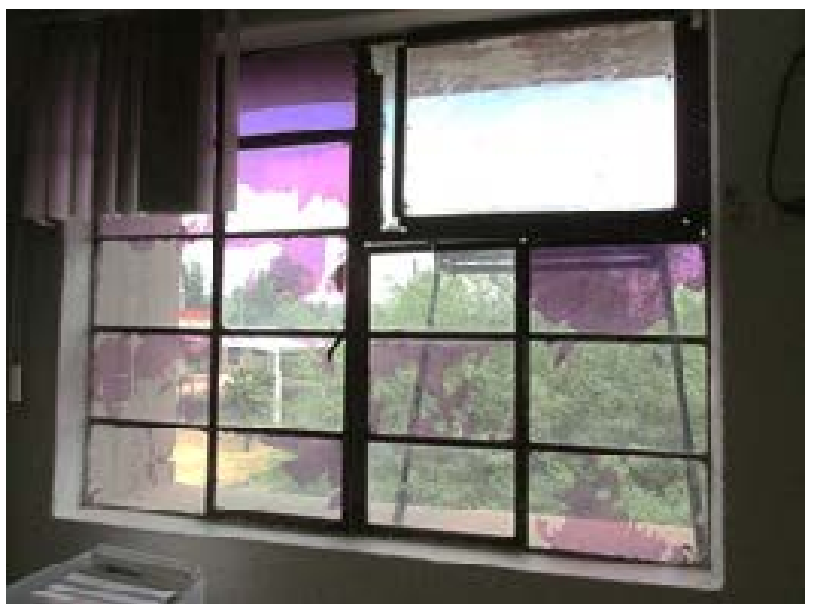

Figure 2. Blacksmith-structured window with damaged polarizer film. Source: Own elaboration. 

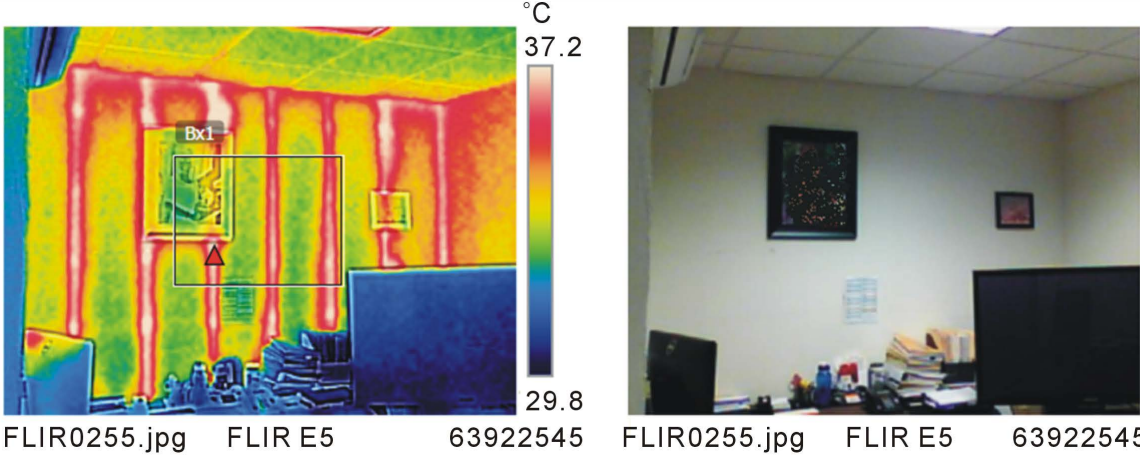

Figure 3. Infrared image and normal picture on an east facing wall. Source: Own elaboration.

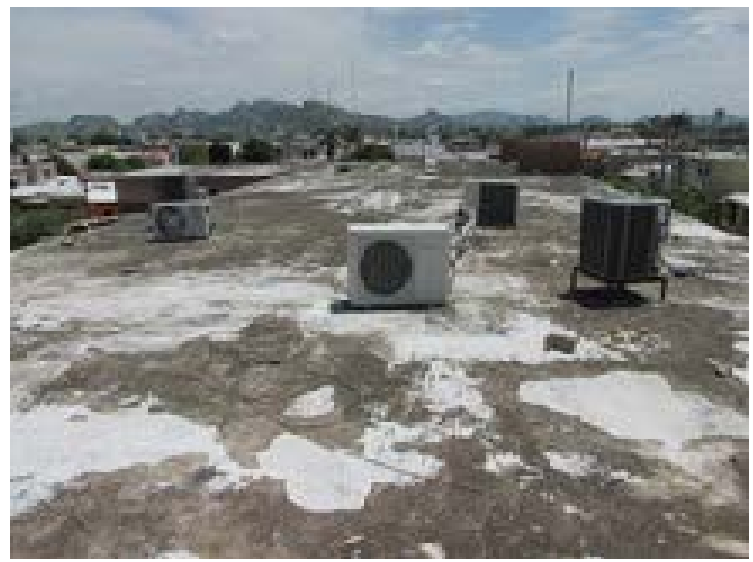

Figure 4. Roof of the main building with south view. Source: Own elaboration.

per $\mathrm{kWh}$ consumed. The month with the greatest demand for electricity was estimated to be from June 16 to July 16, 2016 with a demand of 13,520 kWh. Furthermore, as shown in Table 3, the total area of the building, where $56 \mathrm{em}$ ployees work, is $702.94 \mathrm{~m}^{2}$; therefore, $1720 \mathrm{kWh}$ per capita of energy is consumed with an energy use intensity at $137.02 \mathrm{kWh} / \mathrm{m}^{2} /$ year.

Assuming that on a typical summer day all of the equipment is in use, there is a consumption of $670.98 \mathrm{kWh}$. Thus, if one month has 21 business days, then $14,090.58 \mathrm{kWh}$ are consumed monthly. If this amount is compared with the month of highest consumption, which was recorded at 13,520 kWh, a difference of $570.58 \mathrm{kWh}$ or $4.22 \%$ is estimated, which is very close to the actual value.

When organizing the energy consumption by administrative area on a typical summer day, it can be identified that three areas combined, the Administration and Finance, the Environmental Management, and the Executive Commission, represent $48 \%$ of the total, as detailed in Table 4.

On the other hand, on a typical winter day, when the air conditioning systems are usually turned off, the consumption is estimated at $239.08 \mathrm{kWh}$ per day, having a monthly estimation of $5020.68 \mathrm{kWh}$, with office equipment representing $62 \%$ of the total and lighting $38 \%$. Comparing this estimate with 
Table 3. General electricity consumption-related information.

\begin{tabular}{ccc}
\hline Annual Energy Consumption & Total Area & Number of Employees \\
\hline $96,320 \mathrm{kWh}$ & $702.94 \mathrm{~m}^{2}$ & 56 \\
GHG Emissions & Energy Use Intensity & Consumption per capita \\
44.11 tons of $\mathrm{CO}_{2}$-eq & $137.02 \mathrm{kWh} / \mathrm{m}^{2} /$ year & $1720 \mathrm{kWh}$ \\
\hline
\end{tabular}

Source: Own elaboration.

Table 4. Electricity consumption estimation by administrative area on a typical summer day.

\begin{tabular}{|c|c|c|c|c|c|c|}
\hline Administrative area & $\begin{array}{c}\text { Lighting } \\
\text { kWh }\end{array}$ & $\begin{array}{c}\text { Office } \\
\text { equipment } \\
\text { kWh }\end{array}$ & $\begin{array}{c}\text { Air } \\
\text { conditioning } \\
\text { kWh }\end{array}$ & $\begin{array}{l}\text { Total } \\
\text { kWh }\end{array}$ & $\begin{array}{c}\text { Total } \\
\text { consumption } \\
\%\end{array}$ & $\begin{array}{c}\text { Accumulated } \\
\%\end{array}$ \\
\hline Administration and finance & 13.18 & 49.69 & 55.33 & 118.20 & 18 & 18 \\
\hline Environmental management & 8.74 & 15.82 & 78.89 & 103.44 & 15 & 33 \\
\hline Executive commission & 9.18 & 14.97 & 74.17 & 98.32 & 15 & 48 \\
\hline Common areas & 12.88 & 14.36 & 25.62 & 52.86 & 8 & 56 \\
\hline Purchasing office & 5.46 & 7.18 & 25.90 & 38.54 & 6 & 61 \\
\hline Administrative Control and Development Body & 5.38 & 5.11 & 25.55 & 36.03 & 5 & 67 \\
\hline Human Resources & 1.79 & 7.43 & 22.82 & 32.05 & 5 & 71 \\
\hline General Legal Management & 5.38 & 8.56 & 17.85 & 31.79 & 5 & 76 \\
\hline Conservation & 2.47 & 3.86 & 25.06 & 31.39 & 5 & 81 \\
\hline Technical Coordination & 2.74 & 7.42 & 19.60 & 29.77 & 4 & 85 \\
\hline Meeting room & 2.91 & 0.29 & 22.4 & 25.60 & 4 & 89 \\
\hline Communication & 1.79 & 7.58 & 11.20 & 20.57 & 3 & 92 \\
\hline Exterior lighting & 15.71 & $\mathrm{n} / \mathrm{a}$ & $\mathrm{n} / \mathrm{a}$ & 15.71 & 2 & 95 \\
\hline One-stop shop & 1.79 & 1.16 & 11.20 & 14.15 & 2 & 97 \\
\hline Information technology & 0.45 & 4.74 & 8.40 & 13.59 & 2 & 99 \\
\hline Commissioner Advisor & 0.45 & 0.61 & 7.91 & 8.97 & 1 & 100 \\
\hline Total & 90.30 & 148.78 & 431.90 & 670.98 & & \\
\hline
\end{tabular}

Source: Own elaboration.

the consumption generated between January 16, 2016 and February 16, 2016, a difference of $300.68 \mathrm{~kW}$ or $6.37 \%$ is estimated.

For the purpose of this paper, an emphasis on the AC system was made. Hence, it was determined that the AC system is used for six months a year. Consequently, since it consumes $431.90 \mathrm{kWh}$ on a typical summer day, its yearly consumption is $54,419.40 \mathrm{kWh}$, which is $56.5 \%$ of the total annual electricity consumption, representing an emission value of 24.92 tons of $\mathrm{CO}_{2}$-eq/year.

An installed cooling capacity of $621,799.00 \mathrm{BTU} / \mathrm{h}$ was identified as being 51.82 cooling tons. $36 \mathrm{AC}$ units were recorded including 14 window type units, 
20 mini-split type units, and 2 fan-coil type units. Another aspect to consider is the presence of 12 different AC manufacturers. Due to the absence of a technical plate on some of the equipment, only the refrigerant type for $22 \mathrm{AC}$ units was registered; 19 used refrigerant R22, and three used refrigerant R410A.

In summary, the following opportunities for improvement were found in the AC units along the building.

Window type AC units: see Figure 5 for an example.

- Equipment with vibration problems, most likely caused by unbalanced turbines

- Air leaks in window frames which results in equipment that works without reaching the desired temperature, so the compressor stays on

- Compressors with vibration

- Electrical installations are in poor condition so there is a loss due to lack of adjustment in panels, which cause the wiring and circuit breakers to heat up

- AC air outlet obstruction Mini-split type AC units: See Figure 6 as an example.

- Return and suction lines without lining

- Service valves with loose plugs

- Condensing machines with insufficient anchorage

- Drainage system incorrectly installed so leaks are visible on the walls

- Poor lines installation, which can generate oil traps and damage the compressor

Fan-coil type AC units: See Figure 7 as an example.

- Unlined suction and discharge lines

- Return without a connection to the handler, which results in the equipment works in full camera

- Pipe taken off the air outlet

- Air outlets with an accumulation of dust and dirt

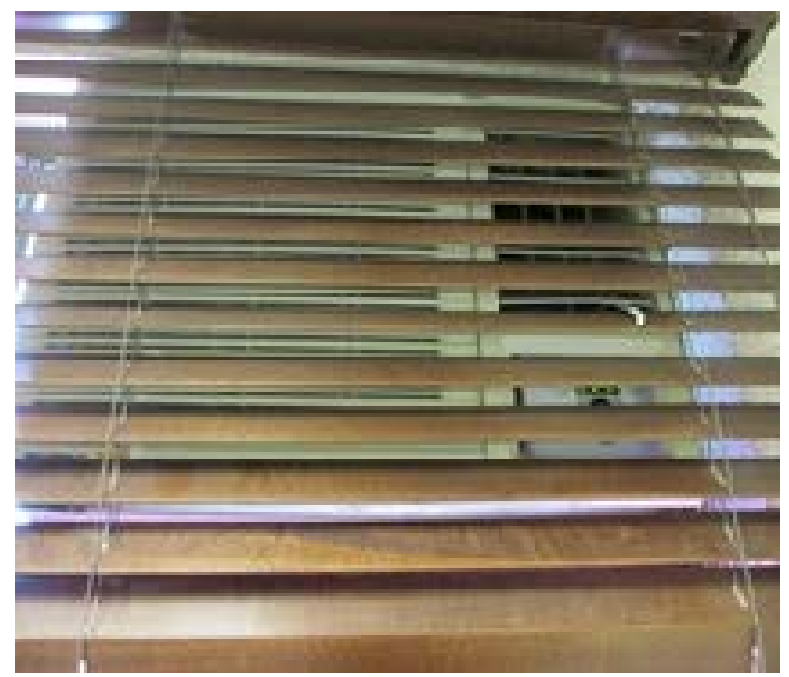

Figure 5. Window type AC unit with air outlet obstruction. Source: Own elaboration. 


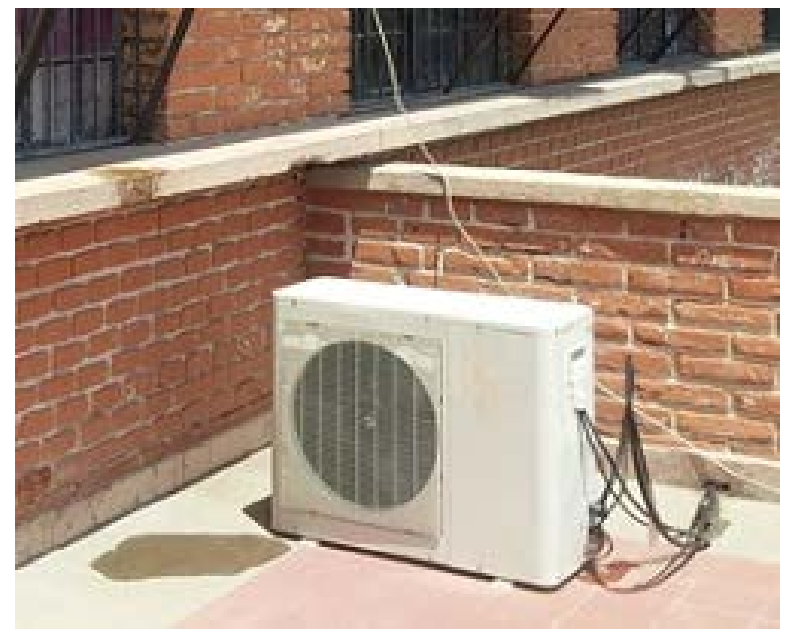

Figure 6. Mini-split type AC unit without lining. Source: Own elaboration.

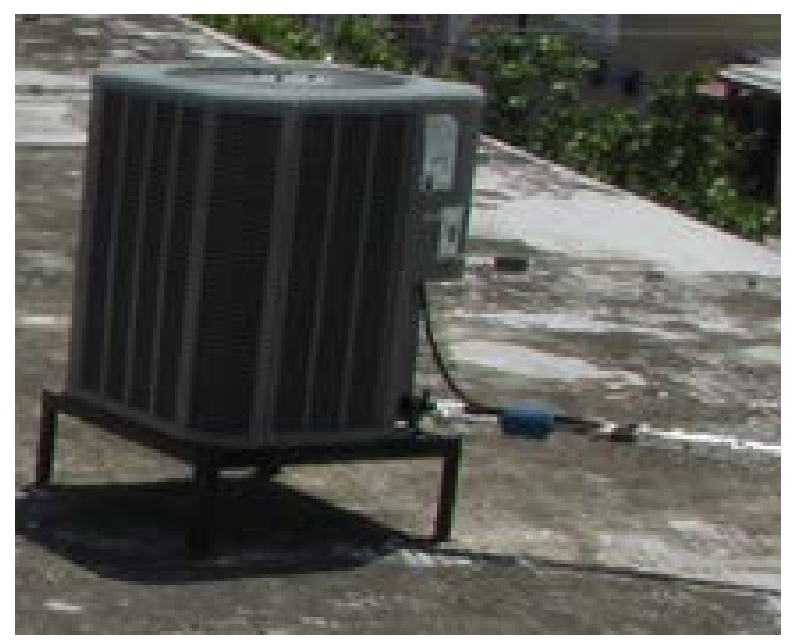

Figure 7. Fan-coil type AC unit with incomplete lining. Source: Own elaboration.

\subsection{Report}

A final report was delivered to the government agency representative with three main proposals related to the AC usage for improving the energy efficiency as well as reducing the environmental impact of the building related to electricity consumption. It is important to highlight that, at the edition time of this paper, these measures still are being analyzed by authorities and their implementation will depend on the decisions made accordingly.

\section{Proposal 1: Improvement of the operation and consumption habits}

In June of 2017, the Code of Ethics and Conduct, as well as the rules of integrity for public employees of the State Public Administration, were published [32], establishing in that human, material, and financial resources accredited as property of the Government or to its service must take into account the criteria of optimization, rationality, austerity, and savings. 
In line with such a code, the first proposed measure is one that requires a lower economic investment. As a first step, employees should be trained about the benefits of carrying out actions that result in energy efficiency, including the three aspects of sustainability, which are social, environmental, and economic.

An internal policy needs to include that during the season when electricity is in high demand from May to October, $\mathrm{AC}$ units must be set to a temperature range from $24^{\circ} \mathrm{C}$ to $26^{\circ} \mathrm{C}$. During operating hours, all doors and windows must remain closed, and, in case of leak-related problems, a report to maintenance personnel needs to be filed. Other possible measures might include disconnecting devices that are not in use and turning off office equipment as well as indoor lights at the end of the workday.

It is important to assign an employee to serve in the role of an energy efficiency supervisor. This position may rotate periodically among the employees in order to strengthen an overall energy efficient culture. This supervisor would have several functions and characteristics, including but not limited to, coordinating the actions aimed at reducing electricity consumption in the building, having access to all offices, and being the only person authorized to handle thermostats and controls. In addition, this individual will turn on the AC progressively, not all at once, at the beginning of the work day, either manually or automatically scheduling that gradual ramp up, and provide reports organized by administrative area to the necessary corresponding authorities.

\section{Proposal 2: Maintenance and reconditioning of facilities}

The current AC units are made by 12 different manufacturers, which makes it difficult to carry seasonal services or to request orders for eventual replacement of components since some of the commercial brands have few roots in the national market. Each piece of equipment has its own specific problems, such as a compressor change, pipe leaks, return lines, unlined suction, a lack of anchoring in condensers, and vibration problems due to unbalanced turbines among others. It is important to install bases for the condensers on the mini-split type AC units to avoid heating if it comes in contact with the roof or a fall due to the vibrations or wind that could potentially damage the operation.

Only two out of the 20 mini-split type AC units installed have a static anchoring system, so the remaining 18 need to be fixed. It is necessary to maintain the AC units, especially the fan-coil type, since a lot of dirt was detected in the exits of the ducts, as well as a duct that had completely decoupled from the ventilation grid, which is causing a reduction in efficiency. The fan-coil type AC units operate by thermostats with basic functions; for this reason, it is proposed to replace them with programmable digital thermostats to automate the operation of the equipment by the day and time. A full diagnostic by an external provider for the whole AC system and implementation of minor measures, as described above, would represent a total investment of \$1400.00 US Dollars.

\section{Proposal 3: Replacement of AC units}

From the 36 AC units, three use refrigerant R410A, and 19 use refrigerant $\mathrm{R} 22$, four of which were recently purchased. The remaining 14 could not be de- 
termined due to the absence of a technical plate on the equipment. Since Mexico ratified the Montreal Protocol in 1987 [33] seeking to reduce production and consumption of ozone-depleting substances, such as chlorofluorocarbons (CFCs), it is important to highlight that the refrigerant R410A has been determined to be less polluting than the R22 [34] [35].

For this reason, the replacement of window type and conventional mini-split type AC units by mini-split type AC units with inverter technology operating with refrigerant R410A would be ideal measure. This change could result in an estimated range of annual electric consumption savings of $4545.42 \mathrm{kWh}$ to 15 $066.59 \mathrm{kWh}$, which translates into avoiding the emission range of 2.08 tons of $\mathrm{CO}_{2}$-eq/year to 6.9 tons of $\mathrm{CO}_{2}$-eq/year. Nevertheless, changing the entire $\mathrm{AC}$ system would require an investment of $\$ 20,000.00$ US Dollars. Since this is a non-profit government entity with limited financial resources, the emphasis must first be on the AC units that could affect the greatest change for the lowest cost investment, and then, as much as possible, gradually change the other units over time.

\section{Final Remarks and Conclusion}

As Mexico is one of the countries that ratified the Montreal Protocol [33] as well as the Paris agreement [36], it is necessary for its government agencies and their facilities to act accordingly. This study may be used as reference for energy efficiency practitioners or decision-making authorities in the public administration field in order to contribute to better energy consumption policies for government buildings. For the case described here, energy audits in the participant government building, with the scope of the AC system, were useful to identify several areas for improvements. If proposals to enhance energy efficiency are carried out properly, at least 2.08 tons of $\mathrm{CO}_{2}$-eq/year can be reduced.

In line with the findings from Dubash et al. [37], regarding the importance of creating new laws on climate change for the public sector, stricter policies for using government buildings more efficiently need to be developed as well. In addition to the potential technical solutions like better maintenance programs, energy use patterns by the employees must be considered in order to have a fully integrated approach for achieving lower environmental impacts through energy efficiency initiatives while also operative costs are reduced.

As a conclusion, AC systems are one of the main contributors to energy consumption, approximately $50 \%$, particularly in arid zones. Therefore, undertaking energy audits may trigger key initiatives that will reduce electricity consumption and improve the energy efficiency in government buildings while still providing a comfortable work environment, by minimizing the facility's potential environmental impacts.

\section{Acknowledgements}

Authors want to thank Luis Federico Olivarría-Ávila, Ana Magdalena Soto- 
mayor-Tovar, Omar Alexis Cabanillas-González, Alan Arnoldo Alcantar-Gómez, and Hilary Platt-Lopez, students of Sustainability Graduate Program at University of Sonora, for their valuable support to the project.

\section{Conflict of Interest Statement}

The authors declare that, to the best of their knowledge, no conflict of interest of any type exists.

\section{References}

[1] UN (1992) United Nations Framework Convention on Climate Change. United Nations, New York.

[2] Mann, M.E. (2009) Do Global Warming and Climate Change Represent a Serious Threat to Our Welfare and Environment? Social Philosophy and Policy, 26, 193-230. https://doi.org/10.1017/S0265052509090220

[3] IPCC (2007) Climate Change 2007: The Physical Science Basis. Contribution of Working Group I to the Fourth Assessment Report of the Intergovernmental Panel on Climate Change. Solomon, S., Qin, D., Manning, M., Chen, Z., Marquis, M., Averyt, K.B., et al., Eds. Cambridge University Press, Cambridge, New York.

[4] Karl, T.T.R. and Trenberth, K.E. (2014) Modern Global Climate Change. Science, 302, 1719-1723. https://doi.org/10.1126/science.1090228

[5] Cook, J., Oreskes, N., Doran, P.T., Anderegg, W.R.L., Verheggen, B., Maibach, E.W., et al. (2016) Consensus on Consensus: A Synthesis of Consensus Estimates on Human-Caused Global Warming. Environmental Research Letters, 11, 1-7. https://doi.org/10.1088/1748-9326/11/4/048002

[6] IPCC. (2014) Climate Change 2014: Impacts, Adaptation, and Vulnerability. Part B: Regional Aspects. Contribution of Working Group II to the Fifth Assessment Report of the Intergovernmental Panel on Climate Change. Barros, V.R., Field, C.B., Dokken, D.J., Mastrandrea, M.D., Mach, K.J., Bilir, T.E., et al., Eds., Cambridge University Press, Cambridge, New York.

[7] Biesbroek, G.R., Swart, R.J. and van der Knaap, W.G.M. (2009) The Mitigation-Adaptation Dichotomy and the Role of Spatial Planning. Habitat International, 33, 230-237. https://doi.org/10.1016/j.habitatint.2008.10.001

[8] VijayaVenkata Raman, S., Iniyan, S. and Goic, R. (2011) A Review of Climate Change, Mitigation and Adaptation. Renewable and Sustainable Energy Reviews, 16, 878-897.

[9] Ford, J.D., Berrang-Ford, L. and Paterson, J. (2011) A Systematic Review of Observed Climate Change Adaptation in Developed Nations. Climatic Change, 106, 327-336. https://doi.org/10.1007/s10584-011-0045-5

[10] Geerts, S. and Raes, D. (2009) Deficit Irrigation as an On-Farm Strategy to Maximize Crop Water Productivity in Dry Areas. Agricultural Water Management, 96, 1275-1284. https://doi.org/10.1016/j.agwat.2009.04.009

[11] UNFCCC (2008) Kyoto Protocol Reference Manual on Accounting of Emissions and Assigned Amount. United Nations Framework Convention on Climate Change, Bonn.

[12] Climate Focus (2015) The Paris Agreement: Summary-Climate Focus Client Brief on the Paris Agreement III. Climate Focus, Amsterdam.

[13] UNFCCC (2015) Climate Change-Get the Big Picture. United Nations Framework 
Convention on Climate Change. http://bigpicture.unfccc.int/

[14] SEMARNAT (2014) El Medio Ambiente en México 2013-2014. Secretaría de Medio Ambiente y Recursos Naturales, Ciudad de México.

[15] SEMARNAT and INECC (2012) México, Quinta Comunicación Nacional ante la Convencion Marco de las Naciones Unidas sobre el Cambio Climático. Secretaría de Medio Ambiente y Recursos Naturales e Instituto Nacional de Ecología y Cambio Climático, Ciudad de México.

[16] Chacón Anaya, D., Giner, M.E., Vázquez Valles, M., Maldonado, J.A., Roe, S.M. and Anderson, R. (2010) Emisiones de gases de efecto invernadero en Sonora y proyecciones de casos de referencia 1990-2020. Border Environment Cooperation Commission, Ciudad Juárez.

[17] IEA (2014) Energy Efficiency Indicators: Fundamentals on Statistics. International Energy Agency, Paris.

[18] SENER (2016) Proyecto de eficiencia y sustentabilidad energética en municipios (PRESEM). Secretaría de Energía, Ciudad de México.

[19] Mihut, A., Duse, D. and Neamtu, M. (2013) Improving the Hospital Management Energy Efficiency Measures. Acta Médica Transilvánica, 2, 213-215.

[20] IEA (2012) Energy Technology Perspectives 2012: Pathways to a Clean Energy System. International Energy Agency, Paris.

[21] SENER (2014) Programa Nacional para el Aprovechamiento Sustentable de la Energía 2014-2018. Secretaría de Energía, Ciudad de México.

[22] Allouhi, A., El Fouih, Y., Kousksou, T., Jamil, A., Zeraouli, Y. and Mourad, Y. (2015) Energy Consumption and Efficiency in Buildings: Current Status and Future Trends. Journal of Cleaner Production, 109, 118-130. https://doi.org/10.1016/j.jclepro.2015.05.139

[23] Mihić, M., Vučković, A. and Vučković, M. (2012) Benefits Management in Energy Efficiency Projects in Serbian Public Buildings. Journal for Theory and Practice Management, 62, 65-74. https://doi.org/10.7595/management.fon.2012.0003

[24] Rahman, M.M. (2009) Building Energy Conservation and Indoor Air Quality Assessment in a Subtropical Climate. Thesis, Central Queensland University, Queensland.

[25] Sterling, E., Collet, C., Turner, S. and Downing, C. (1992) Commissioning to Avoid Indoor Air Quality Problems. ASHRAE Journal, 34, 28-32.

[26] ISO (2011) Norma Internacional ISO 50001 Sistemas de gestión de la energía, requisitos con orientación para su uso. Organización Internacional de Normalización, Geneva.

[27] Barbetta, G.P., Canino, P. and Cima, S. (2015) The Impact of Energy Audits on Energy Efficiency Investment of Public Owners. Evidence from Italy. Energy, 93, 1199-209. https://doi.org/10.1016/j.energy.2015.09.117

[28] Kelsey, J. and Pearson, D. (2011) Updated Procedures for Commercial Building Energy Audits. Annual Conference of the American Society of Heating Refrigerating and Air Conditioning Engineers, Montreal, 374-381.

[29] ASHRAE (2013) 2013 ASHRAE Handbook Fundamentals. American Society of Heating, Refrigerating and Air-Conditioning Engineers, Atlanta.

[30] SEMARNAT (2017) Registro Nacional de Emisiones RENE. Secretaría de Medio Ambiente y Recursos Naturales, Ciudad de México.

[31] XE.com (2018) Conversor de divisas XE. 
http://www.xe.com/es/currencyconverter/convert/?Amount=2\&From=MXN\&To= USD

[32] Gobierno del Estado de Sonora (2017) Acuerdo por el que se emiten el Código de Ética y Conducta, y las reglas de integridad para los servidores públicos de la Administración Pública Estatal. Boletín Oficial. Gobierno del Estado de Sonora, Hermosillo.

[33] SEMARNAT (2016) Apoya México enmienda a Protocolo de Montreal para combatir el cambio climático. Press Release. Secretaría de Medio Ambiente y Recursos Naturales, Ciudad de México.

[34] Bitzer (2016) Refrigerant Report 19. Bitzer Kühlmaschinenbau GmbH, Sindelfingen.

[35] Bolaji, B.O. (2012) Performance of a R22 Split-Air-Conditioner When Retrofitted with Ozone Friendly Refrigerants (R410A and R417A). Journal of Energy in Southern Africa, 23, 16-22.

[36] SRE (2017) Mexico Reaffirms Its Support for and Commitment to the Paris Agreement to Halt the Effects of Global Climate Change. Press Release. Secretaría de Relaciones Exteriores, Mexico City.

[37] Dubash, N.K., Hagemann, M., Höhne, N. and Upadhyaya, P. (2014) Developments in National Climate Change Mitigation Legislation and Strategy. Climate Policy, 14, 649-664. 